SHORT COMMUNICATION

\title{
Calcium Carbonate/Polymer Thin-Film Hybrids: Induction of the Formation of Patterned Aragonite Crystals by Thermal Treatment of a Polymer Matrix
}

\author{
By Takeshi SAKAmoto, Akira OICHI, Tatsuya Nishimura, Ayae SugaWARA, and Takashi Kato*
}

KEY WORDS: Self-Organization / Biomineralization / Crystal Growth / $\mathrm{CaCO}_{3}$ / Poly(vinyl alcohol) /

Biominerals are inorganic/organic composites formed by living organisms. ${ }^{1}$ Bio-inspired approaches to the control of $\mathrm{CaCO}_{3}$ crystallization led to the formation of a variety of crystalline shapes in the presence of organic polymer templates and/or additives..$^{2-5}$ Moreover, a variety of inorganic/polymer hybrids have been prepared. ${ }^{3-18}$ It is not easy to control ordered and hierarchical structures of inorganic/organic composites as biominerals. Herein we report on self-organization of $\mathrm{CaCO}_{3} /$ polymer composite films with regularly patterned structures. The morphologies were tuned by thermal treatment of the polymer matrices. The morphologies and polymorphs of the $\mathrm{CaCO}_{3}$ films grown on the matrices of poly[(vinyl alcohol)-co-(vinyl acetate)] (polymer 1) in the presence of poly(acrylic acid) (polymer 2) were varied by the annealing time of the matrices (Figure 1). Polymer 2 interacts with the ions and the matrices., ${ }^{3,8-10}$

We reported that $\mathrm{CaCO}_{3}$ thin films with periodically patterned structures were self-organized on the thin-film matrices of polymers forming hydrogels such as modified polysaccharides. ${ }^{89}$ However, formation mechanisms for the patterned structures and effects of the matrices on the regular structures are still unclear. In addition, the polymorph of the patterned $\mathrm{CaCO}_{3}$ was only calcite, which is the most stable state. In the present study, we have chosen a film of polymer $\mathbf{1}$ as a matrix for the crystal growth of $\mathrm{CaCO}_{3}$. The used film was thicker than that used in a previous study. ${ }^{9}$ Polymer 1 forms hydrogel and it may affect the polymorphs of $\mathrm{CaCO}_{3} \cdot{ }^{10,11}$ We expected that these properties were of advantage for the control of crystallization. The structures and properties of poly(vinyl alcohol)-based polymers were easily modified through the chemical modification and/or thermal treatment.

Film matrices of polymer 1 were prepared by spin-coating onto glass substrates and subsequent thermal annealing at $200^{\circ} \mathrm{C}$. These matrices were immersed into aqueous solutions of calcium chloride $(10 \mathrm{mM})$ containing polymer 2 with average molecular weight of $2.0 \times 10^{3}(2.4 \times$ $\left.10^{-3} \mathrm{wt} \%\right) . \mathrm{CaCO}_{3}$ was crystallized by slowly diffusing ammonium carbonate vapor into the calcium chloride solution at $30^{\circ} \mathrm{C}$.

Figure 2 shows the images of scanning electron microscopy (SEM) and polarizing optical microscopy for the obtained crystals. The SEM image of the $\mathrm{CaCO}_{3}$ hybrid film grown on the polymer 1 matrix annealed for $10 \mathrm{~min}$ shows that periodic surface-relief structure is spontaneously formed (Figure 2a, left). The periodicity of the concentric relief structures is about $850 \mathrm{~nm}$ and the height of the relief is about $100 \mathrm{~nm}$. The measurements of Fourier transform infrared and X-ray diffraction (Figure 3) for the hybrids have revealed that the polymorph of the film crystal is aragonite. The dendritic aragonite film is formed on the matrix of polymer $\mathbf{1}$ annealed for $60 \mathrm{~min}$ (Figure 2b, left). In contrast, the calcite film is formed on the matrix annealed for $120 \mathrm{~min}$. This thin film displays concentric ring structure (Figure 2c, left) different from that of the aragonite film (Figure 2a, left).

The observation of the hybrid with a polarizing optical microscope shows that the aragonite film with the concentric patterns exhibits crossed

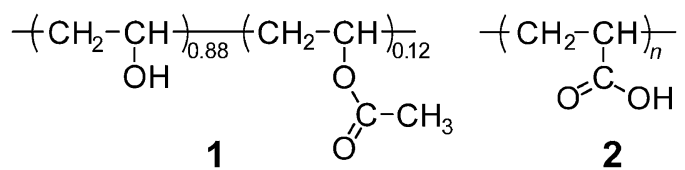

Figure 1. Structures of poly[(vinyl alcohol)-co-(vinyl acetate)] (polymer 1) and poly(acrylic acid) (polymer 2).
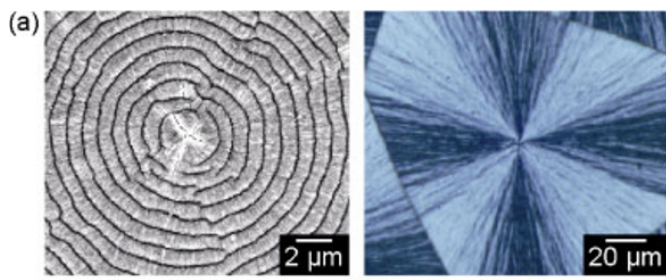

(b)
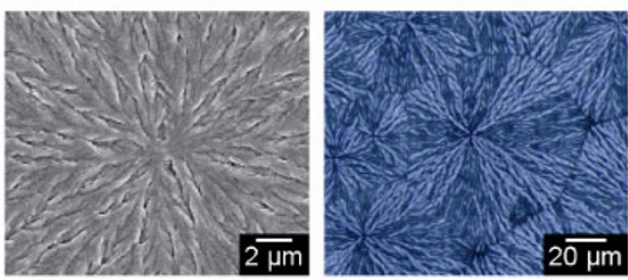

(c)
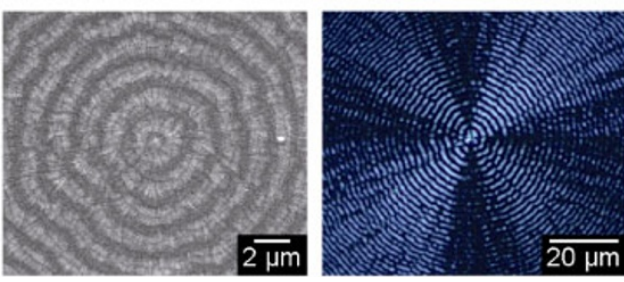

Figure 2. $\mathrm{CaCO}_{3}$ crystals grown on the matrices of polymer 1 annealed at $200^{\circ} \mathrm{C}$ for (a) 10 , (b) 60 , and (c) $120 \mathrm{~min}$, in the presence of polymer $2\left(2.4 \times 10^{-3} \mathrm{wt} \%\right)$. Left: scanning electron microscopic (SEM) images; right: polarized optical microscopic images.

extinction due to the radial orientation of the $c$ axes (Figure 2a, right). The dendritic aragonite films also show the crossed extinction although it is indistinct (Figure 2b, right). In contrast, the concentric calcite film shows concentric dark rings (Figure 2c, right). This birefringence pattern indicates that the $c$ axes in the disklike calcite film are alternately aligned perpendicularly (dark ring areas) and parallel (bright ring areas) to the radial direction ${ }^{9,12}$

Department of Chemistry and Biotechnology, School of Engineering, The University of Tokyo, Hongo, Bunkyo-ku, Tokyo 113-8656, Japan

*To whom correspondence should be addressed (Tel: +81-3-5841-7440, Fax: +81-3-5841-8661, E-mail: kato@ chiral.t.u-tokyo.ac.jp). 


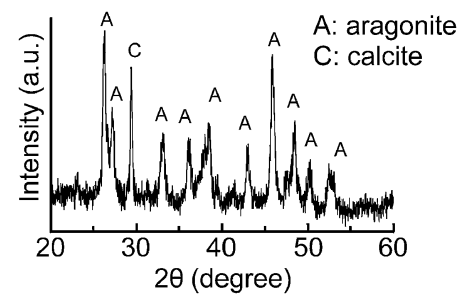

Figure 3. X-Ray diffraction pattern of aragonite crystals grown on the polymer $\mathbf{1}$ matrix annealed for $10 \mathrm{~min}$ in the presence of polymer 2.
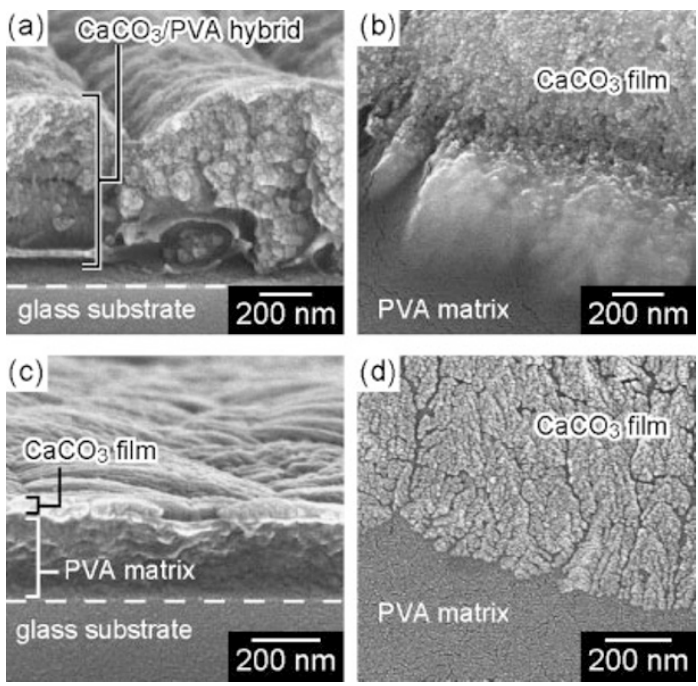

Figure 4. SEM images of the $\mathrm{CaCO}_{3}$ films on the matrices of polymer 1 annealed for $(a, b) 10$ and $(c, d) 120 \mathrm{~min}$. (a,c) Cross sections and $(b, d)$ growing fronts of the crystal films observed from above.

The fractured cross-sections and the areas around growing fronts of the $\mathrm{CaCO}_{3}$ films are shown in Figure 4. The concentric aragonite film is composed of nanocrystals formed in the film matrix of polymer $\mathbf{1}$ annealed for $10 \mathrm{~min}$ (Figure 4a). At the front of the $\mathrm{CaCO}_{3}$ film, we see next ridge parts of the relief structures growing from inside of the matrix (Figure $4 b$ ). The dendritic aragonite film is also composed of the nanocrystals formed inside of the matrix annealed for $60 \mathrm{~min}$. In contrast, the concentric calcite film is composed of the crystals formed mainly on the surface of the polymer 1 matrix (Figure 4c,d).

We studied the effects of the thermal treatment on swelling behavior of the matrices by SEM observation for the matrices after immersion in water and subsequent freeze-drying process. The matrix annealed for 10 min was swollen. The thickness became twice by the immersion. In contrast, the matrices annealed for $60 \mathrm{~min}$ showed little swelling. The same behavior was observed for the sample annealed for $120 \mathrm{~min}$. The crosslinking by the annealing for $60 \mathrm{~min}$ might be enough for the polymer to show little swelling.

The degrees of polymer crosslink dependent on the annealing time affect the crystallization conditions such as diffusion rates and concentrations of the ions. We consider that the patterned structures of $\mathrm{CaCO}_{3}$ obtained in the present study have generated through competitions between the consumption and diffusion of the ions. ${ }^{8,9,13}$
The formation of aragonite crystals was induced by organic matrices ${ }^{10,11,15-17}$ and inorganic ions. ${ }^{18}$ In the present study, the crystallization inside the matrices of polymer 1 has resulted in the selective formation of aragonite. It has been reported that poly(vinyl alcohol) induces aragonite formation as a insoluble substrate ${ }^{10}$ or a soluble additive. ${ }^{11}$ This behavior is explained as results from the geometrical effects of the polymer or stabilization effects by the polymer adsorption. In this study, the aragonite formation was induced by these effects of the polymer $\mathbf{1}$ matrix.

Acknowledgment. This study was partially supported by Grant-in-aid for The Global COE Program "Chemistry Innovation through Cooperation of Science and Engineering" (T.K., T.S.), Exploratory Research (No. 20655022) (T.K.), and Encouragement of Young Scientists B (No. 19750106) (T.N.) from MEXT. T.S. is thankful for financial support from JSPS Research Fellowships for Young Scientists (No. 209962).

Received: January 27, 2009

Accepted: March 18, 2009

Published: May 13, 2009

\section{REFERENCES}

1. S. Mann, in "Biomineralization," R. G. Compton, S. G. Davies, and J. Evans, Ed., Oxford University Press, Oxford, 2001.

2. F. C. Meldrum, Int. Mater. Rev., 48, 187 (2003).

3. T. Kato, A. Sugawara, and N. Hosoda, Adv. Mater., 14, 869 (2002).

4. K. Naka and Y. Chujo, Chem. Mater., 13, 3245 (2001).

5. H. Imai, Y. Oaki, and A. Kotachi, Bull. Chem. Soc. Jpn., 79, 1834 (2006).

6. W. Tachaboonyakiat, T. Serizawa, and M. Akashi, Polym. J., 33, 177 (2001).

7. K. Yamamoto, T. Otsuka, S.-I. Wada, D. Sohn, and A. Takahara, Soft Matter, 1, 372 (2005).

8. a) A. Sugawara, T. Ishii, and T. Kato, Angew. Chem., Int. Ed., 42, 5299 (2003).

b) T. Sakamoto, A. Oichi, A. Sugawara, and T. Kato, Chem. Lett., 35, 310 (2006).

9. T. Sakamoto, A. Oichi, Y. Oaki, T. Nishimura, A. Sugawara, and T. Kato, Cryst. Growth Des., 9, 622 (2009).

10. N. Hosoda, A. Sugawara, and T. Kato, Macromolecules, 36, 6449 (2003).

11. R. Lakshminarayanan, S. Valiyaveettil, and G. L. Loy, Cryst. Growth Des., 3, 953 (2003).

12. A. Sugawara, A. Oichi, H. Suzuki, Y. Shigesato, T. Kogure, and T. Kato, J. Polym. Sci., Part A: Polym. Chem., 44, 5153 (2006).

13. T. Wang, A.-W. Xu, and H. Cölfen, Angew. Chem., Int. Ed., 45, 4451 (2006).

14. B. Talukdar, Y. Takaguchi, Y. Yanagimoto, S. Tsuboi, M. Ichihara, and K. Ohta, Bull. Chem. Soc. Jpn., 79, 1983 (2006).

15. A. Kotachi, T. Miura, and H. Imai, Cryst. Growth Des., 6, 1636 (2006).

16. Y. Levi, S. Albeck, A. Brack, S. Weiner, and L. Addadi, Chem. Eur. J., 4, 389 (1998).

17. N. Nassif, N. Gehrke, N. Pinna, N. Shirshova, K. Tauer, M. Antonietti, and H. Cölfen, Angew. Chem., Int. Ed., 44, 6004 (2005).

18. a) A. Sugawara and T. Kato, Chem. Commun., 487 (2000). b) A. Sugawara and T. Kato, Compos. Interfaces, 11, 287 (2004). 